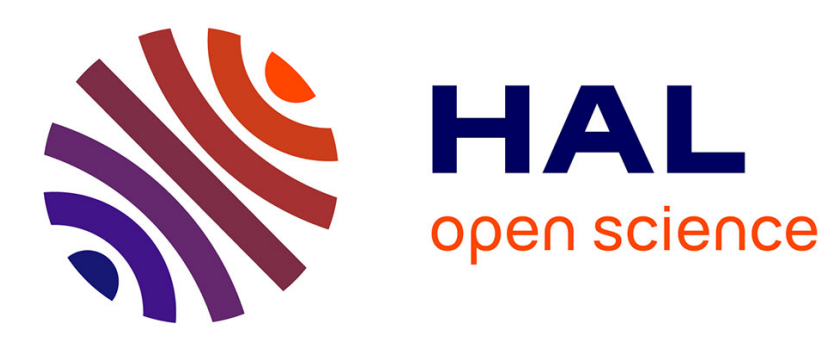

\title{
L1 Adaptive Control of a Lower Limb Exoskeleton Dedicated to Kids' Rehabilitation
}

\author{
Boutheina Maalej, Ahmed Chemori, Nabil Derbel
}

\section{To cite this version:}

Boutheina Maalej, Ahmed Chemori, Nabil Derbel. L1 Adaptive Control of a Lower Limb Exoskeleton Dedicated to Kids' Rehabilitation. New Trends in Robot Control, 270, pp.107-129, 2020, 978-981-151818-8. 10.1007/978-981-15-1819-5_6. lirmm-02478654

\section{HAL Id: lirmm-02478654 https://hal-lirmm.ccsd.cnrs.fr/lirmm-02478654}

Submitted on 14 Feb 2020

HAL is a multi-disciplinary open access archive for the deposit and dissemination of scientific research documents, whether they are published or not. The documents may come from teaching and research institutions in France or abroad, or from public or private research centers.
L'archive ouverte pluridisciplinaire HAL, est destinée au dépôt et à la diffusion de documents scientifiques de niveau recherche, publiés ou non, émanant des établissements d'enseignement et de recherche français ou étrangers, des laboratoires publics ou privés. 


\title{
$L_{1}$ Adaptive Control of a Lower Limb Exoskeleton Dedicated to Kids' Rehabilitation
}

\author{
Boutheina Maalej, Ahmed Chemori and Nabil Derbel
}

B. Maalej $(\varangle) \cdot$ N. Derbel

Laboratory of Control \& Energy Management, ENIS, Digital Research Center of Sfax, University of Sfax, Sfax, Tunisia

e-mail: maalej.boutheina@gmail.com

N. Derbel

e-mail: n.derbel@enis.rnu.tn

B. Maalej

Clinical Investigation Center, University of Gabes, Sfax, Tunisia

\section{A. Chemori}

LIRMM, University of Montpellier, Montpellier, France

e-mail: ahmed.chemori@lirmm.fr 
robotic rehabilitation. There exist several disabilities that may cause the movement disorders and affect the brain which is the responsible of the body functions. Any damage in the brain tissue before, during or after childbirth may affect certain areas of the brain. Besides, depending on the degree of injury, it can cause permanent disorders, characteristic of a non-progressive injury. Among the potentially determining factors of irreversible brain damage, the most frequently observed include infections of the nervous system, hypoxia (lack of oxygen), head injuries, etc. Children with cerebral motor disorders represent 3 per 1000 newborns. In this context, several medical applications appear in order to help paralyzed kids to restore their locomotion. In this work, we consider the case of lower limb rehabilitation using exoskeletons in order to assist children movements. In the sequel, we will be interested in kids who have between 2 and 13 years old. Hence, we propose to implement robust controllers that can be adapted to the difference of children morphologies [10]. An adaptive control is a controller with adjustable parameters. In fact, it can adapt to changes in the process dynamics and the disturbance characteristics. Moreover, adaptive techniques can also be used to provide automatic tuning of controllers. In this chapter, four control laws are proposed to solve the problem of parametric variations. The chosen controllers include two nonlinear state feedback adaptive controllers, the $L_{1}$ adaptive control and augmented $L_{1}$ adaptive control. The first approach, based on Slotine works [12], consists in a PD feedback part and a full dynamic feedforward tacking into consideration parametric variations. The second approach is also based on Slotine works [12]. It consists in adding an integral control action to the previous approach in order to eliminate undesirable steady-state position errors. The third approach consists in applying $L_{1}$ adaptive control proposed by Naira Hovakimyan [7]. The fourth approach is the augmented $L_{1}$ adaptive control [9] which combines the $L_{1}$ adaptive control with a Proportional-Integral control to eliminate the time lag and to improve the tracking performances. Simulation results will be presented with a comparative study which aims to show the robustness of the augmented $L_{1}$ adaptive control.

\section{Description and Modeling of Exoskeletons}

Exoskeletons are made in order to help kids suffering from several diseases, such as the cerebral palsy, to restore their walk again by a cyclical and alternative rhythmic activities. The basic idea is to control the lower limb exoskeleton (Fig. 1) at the hip and knee joints.

The dynamic model includes the human limb and the exoskeleton, it is written as follows [5]:

$$
M(q) \ddot{q}+C(q, \dot{q}) \dot{q}+G(q)=\tau
$$

with, 
Fig. 1 Concept of the 2-joint lower limb exoskeleton

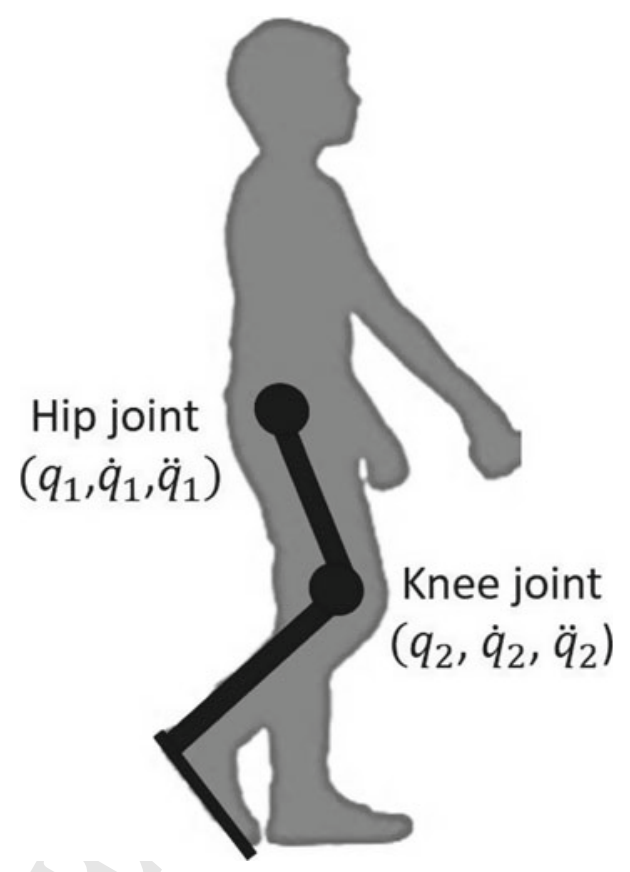

$M_{11}=\frac{1}{8} l_{1}^{2} m_{1}+\frac{1}{4} m_{2}\left(\frac{1}{4} l_{2}^{2}+l_{1}^{2}+l_{1} l_{2} \cos q_{2}\right)+\frac{1}{2} m_{s}\left(l_{1}^{2}+l_{2}^{2} k_{2}^{2}+2 l_{1} l_{2} k_{2} \cos q_{2}\right)$

$$
+\frac{1}{2} k_{1}^{2} l_{1}^{2} m_{t}+\frac{1}{2}\left(I_{1}+I_{2}+I_{s}+I_{t}\right)
$$

$M_{12}=M_{21}=\frac{1}{2} m_{2}\left(\frac{1}{2} l_{2}^{2}+l_{1} l_{2} \cos q_{2}\right)+\frac{1}{2} m_{s}\left(l_{2}^{2} k_{2}^{2}+2 l_{1} l_{2} k_{2} \cos q_{2}\right)+\left(I_{2}+I_{s}\right)$

$M_{22}=\frac{1}{8} m_{2} l_{2}^{2}+\frac{1}{2} m_{s} l_{1}^{2}+l_{2}^{2} k_{2}^{2}+\frac{1}{2}\left(I_{2}+I_{s}\right)$

$C_{11}=\left(\frac{1}{2} m_{2}+m_{s} k_{2}\right) l_{1} l_{2} \sin q_{2}$

$C_{12}=-\left(\frac{1}{2} m_{2}+m_{s} k_{2}\right) l_{1} l_{2} \sin q_{2}$

$C_{21}=\left(\frac{1}{4} m_{2}+1 / 2 m_{s} k_{2}\right) l_{1} l_{2} \sin q_{2}$

$C_{22}=0$

$G_{1}=-\left(\frac{1}{2} m_{1}+m_{2}+k_{1} m_{t}+m_{s}\right) g l_{1} \sin q_{1}-\left(1 / 2 m_{1}+m_{s} k_{2}\right) g l_{2} \sin \left(q_{1}+q_{2}\right)$

$G_{2}=-\left(\frac{1}{2} m_{1}+m_{s} k_{2}\right) g l_{2} \sin \left(q_{1}+q_{2}\right)$ 


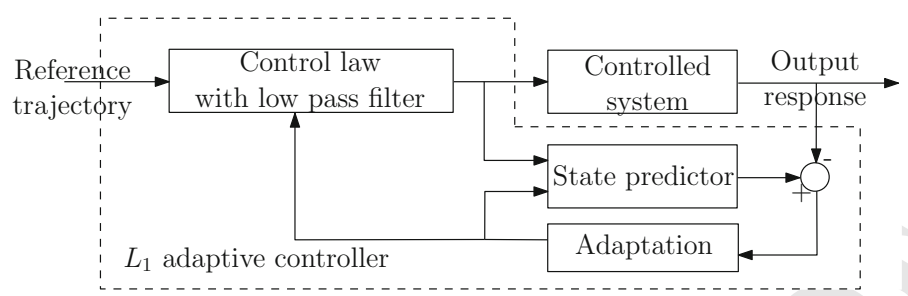

Fig. 2 Block diagram of $L_{1}$ adaptive control [7]

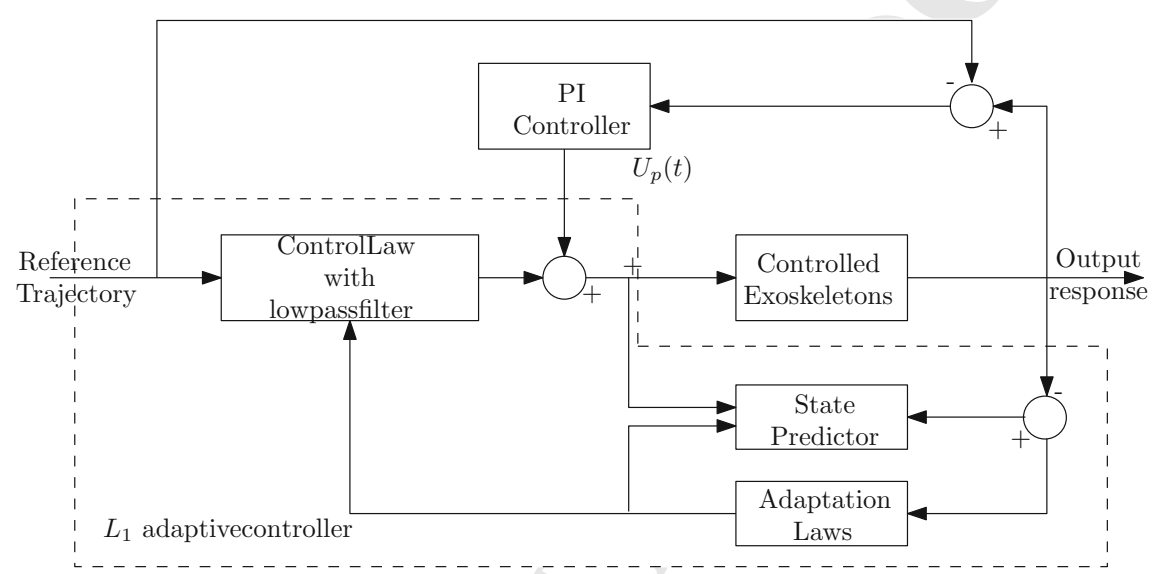

Fig. 3 Block diagram of the augmented $L_{1}$ adaptive control [2]

where:

$q=\left[q_{1} q_{2}\right]^{T} \in \mathbb{R}^{2}$ represents the position vector of the hip and knee joints, respectively,

$\dot{q}=\left[\dot{q}_{1} \dot{q}_{2}\right]^{T} \in \mathbb{R}^{2}$ is the speed vector,

$\ddot{q}=\left[\begin{array}{ll}\ddot{q}_{1} & \ddot{q}_{2}\end{array}\right]^{T} \in \mathbb{R}^{2}$ is the acceleration vector,

$M(q) \in \mathbb{R}^{2}$ is the inertia matrix, which is symmetric, uniformly bounded and positive definite,

$C(q, \dot{q}) \dot{q} \in \mathbb{R}^{2}$ represents the Coriolis, and centrifugal forces and torques,

$G(q) \in \mathbb{R}^{2}$ denotes the gravity torques,

$\tau \in \mathbb{R}^{2}$ is the vector of actuator torques,

$m_{1}, m_{2}, l_{1}, l_{2}$ represent the mass and length of thigh and shank segments of the exoskeleton, respectively,

$m_{t}, m_{s}$ denote thigh and shank masses of human limb,

$k_{1}, k_{2}$ are the position of the center of mass of thigh and shank segments, respectively, $I_{1}, I_{2}, I_{s}, I_{t}$ represent the moments of inertia of thigh and shank of the exoskeleton and human limb, respectively,

$g$ is the gravity acceleration. 

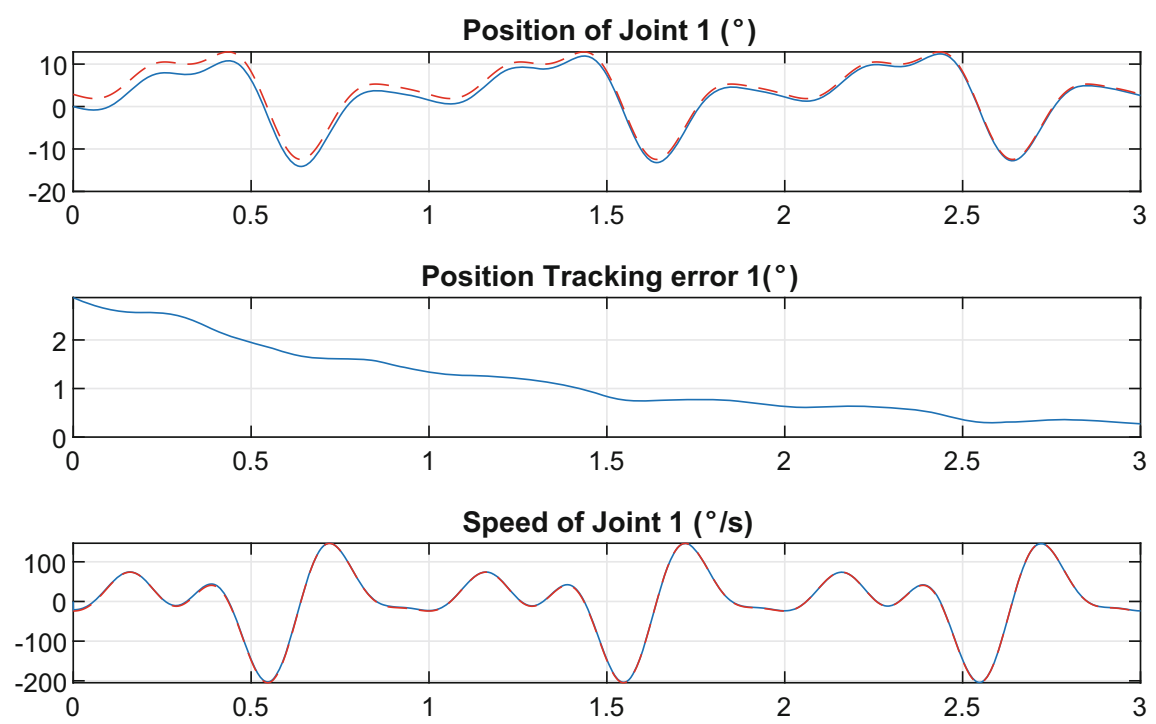

Torque control of Joint $1(\mathrm{Nm})$

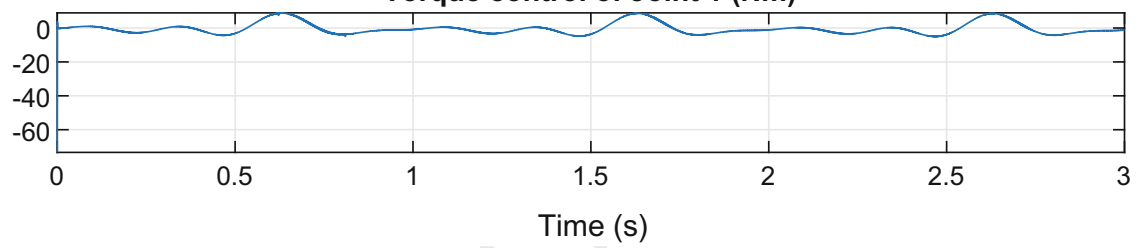

Fig. 4 Classical adaptive control of the hip joint. For the position and the speed, dashed line: desired trajectory, solid line: actual trajectory

\section{Proposed Control Solution}

\subsection{Adaptive Control [12]}

Let consider that $q_{d}$ is the desired joint position and $\dot{q}_{d}$ is the desired velocity. The main idea is to develop a globally stable adaptive controller which is obtained from 6 a Lyapunov stability analysis. The Lyapunov function associated to the system is:

$$
V(t)=\frac{1}{2}\left[\dot{\tilde{q}}^{T} M(q) \dot{\widetilde{q}}+\widetilde{a}^{T} \Gamma \tilde{a}+\widetilde{q}^{T} K_{p} \widetilde{q}\right]
$$

where

$a$ : represents the vector of unknown manipulator parameters

$\widehat{a}:$ represents its estimate

$\widetilde{a}=\widehat{a}-a:$ denotes the parameter estimation error vector 

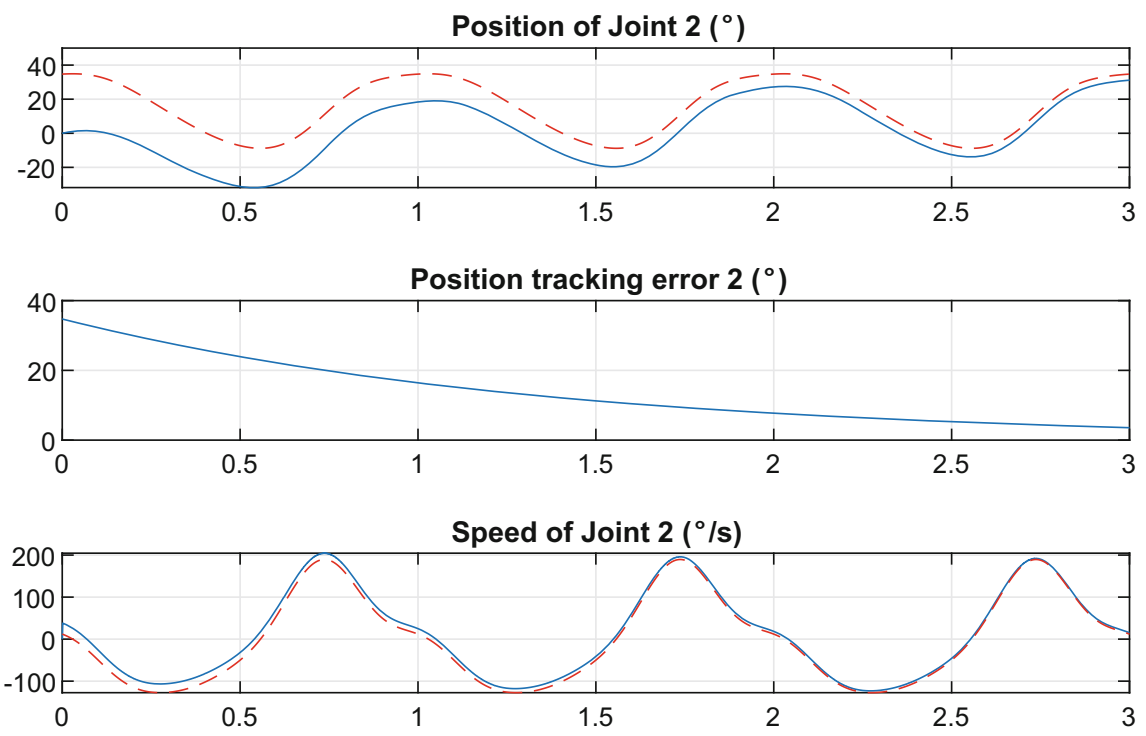

Torque control of Joint $2(\mathrm{Nm})$

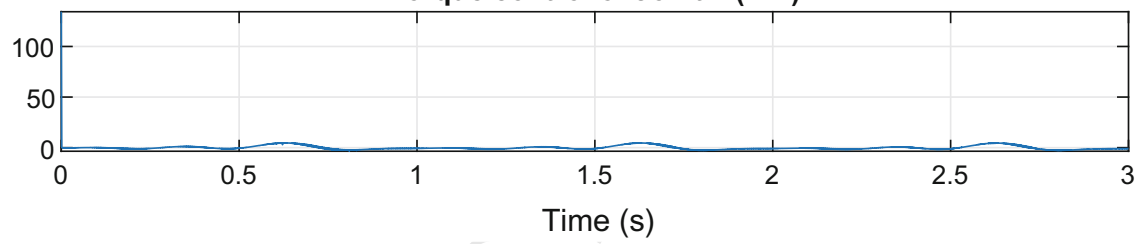

Fig. 5 Classical adaptive control of the knee joint. For the position and the speed, dashed line: desired trajectory, solid line: actual trajectory

$K_{p}, \Gamma$ : symmetric positive definite matrices

$\widetilde{q}=q-q_{d}$ : represents the position tracking error

$\ddot{q}=\dot{q}-\dot{q}_{d}$ : represents the velocity tracking error

The derivative of $V$ with respect to time is:

$$
\begin{aligned}
\dot{V}(t)= & \dot{\tilde{q}}^{T} M \ddot{\widetilde{q}}+\frac{1}{2} \dot{\tilde{q}}^{T} M \dot{\widetilde{q}}+\widetilde{a}^{T} \Gamma \dot{\tilde{a}}+\widetilde{q}^{T} K_{p} \dot{\tilde{q}} \\
= & \dot{\tilde{q}}^{T}\left(\tau-C(q, \dot{q}) \dot{q}-G(q)-M \ddot{q}_{d}\right)+\dot{\tilde{q}}^{T}\left(\frac{1}{2}(\dot{M}-2 C)+C\right) \dot{\tilde{q}} \\
& +\tilde{a}^{T} \Gamma \dot{\tilde{a}}+\dot{\tilde{q}}^{T} K_{p} \widetilde{q} \\
= & \dot{\widetilde{q}}^{T}\left(\tau-M(q) \ddot{q}_{d}-C(q, \dot{q}) \dot{q}_{d}-G(q)+K_{p} \tilde{q}\right)+\tilde{a}^{T} \Gamma \dot{\widetilde{a}}
\end{aligned}
$$

Using the property of skew symmetric matrix, we have: 

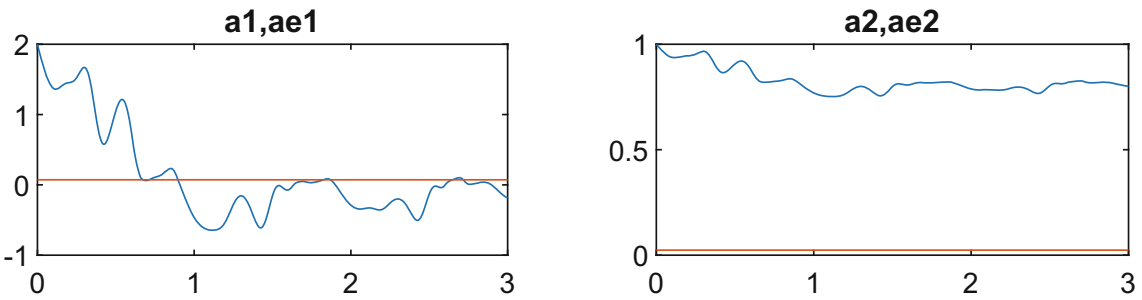

a3,ae3
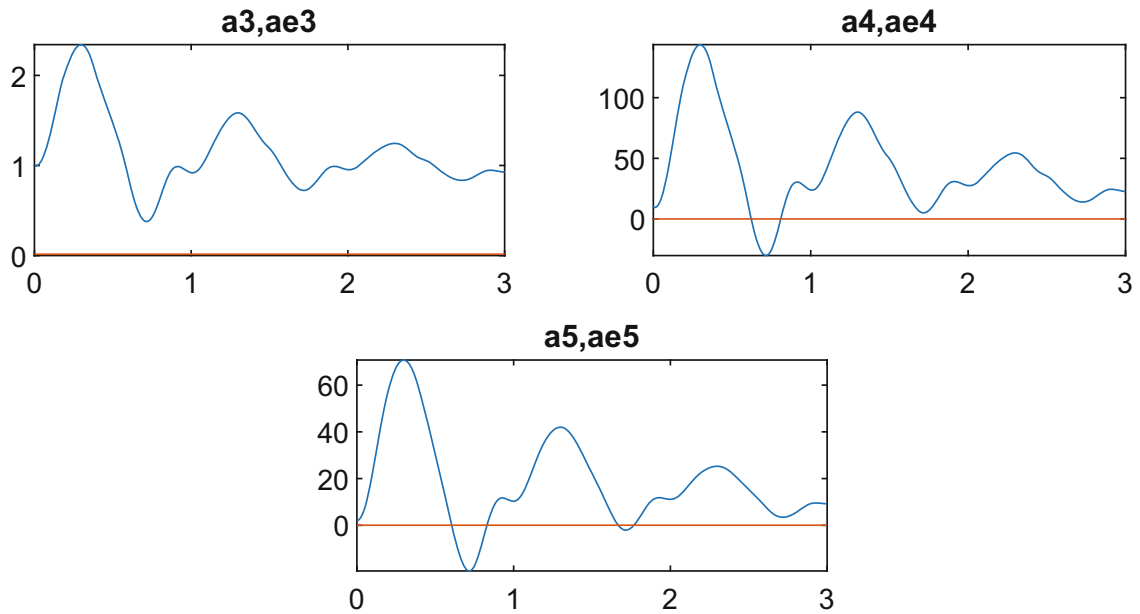

Fig. 6 Evolution of the estimated Parameters for the first approach of Slotine

$$
\begin{aligned}
& \frac{1}{2} \frac{d}{d t}\left(\dot{q}^{T} M \dot{q}\right)=\dot{q}^{T}(\tau-G(q)) \\
& \dot{q}^{T}\left(\frac{1}{2} \dot{M}-C\right) \dot{q}=0
\end{aligned}
$$

Considering the following control law:

$$
\tau=\widehat{M} \ddot{q}_{d}+\widehat{C}(q, \dot{q})+\widetilde{G}(q)-K_{p} \widetilde{q}-K_{D} \dot{\tilde{q}}
$$

gives

$$
\dot{V}=\dot{\widetilde{q}}^{T}\left[\widetilde{M}(q) \ddot{q}_{d}+\widetilde{C}(q, \dot{q}) \dot{q}_{d}+\widetilde{G}(q)-K_{D} \dot{\widetilde{q}}\right]+\widetilde{a}^{T} \Gamma \dot{\tilde{a}}
$$

where: 
Position of Joint $1\left(^{\circ}\right)$

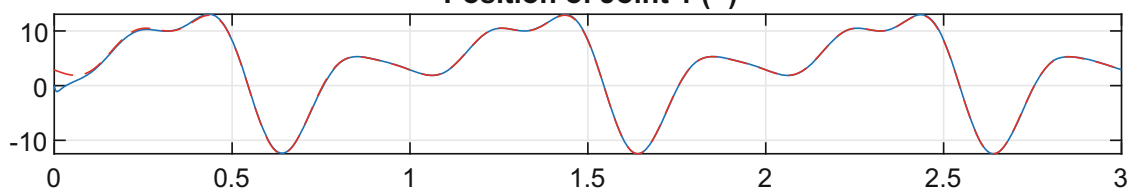

Position Tracking error $1\left(^{\circ}\right)$

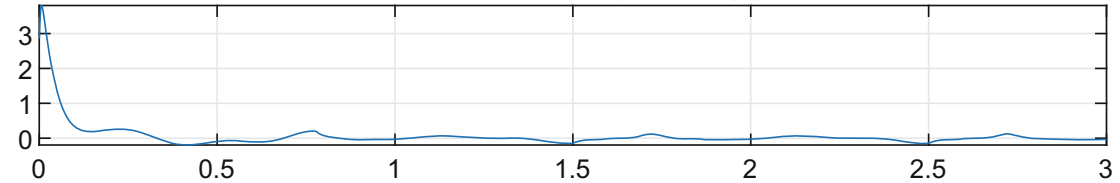

Speed of Joint $1\left({ }^{\circ} / \mathrm{s}\right)$

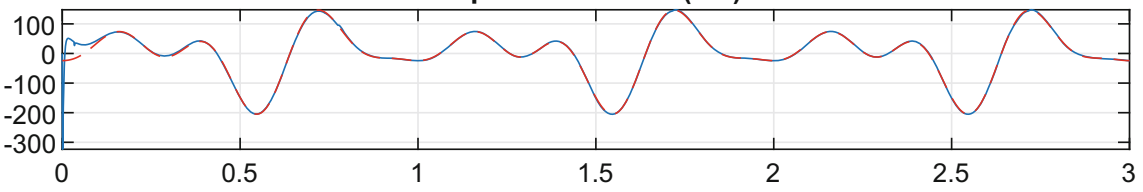

Torque control of Joint 1 ( $\mathrm{Nm})$

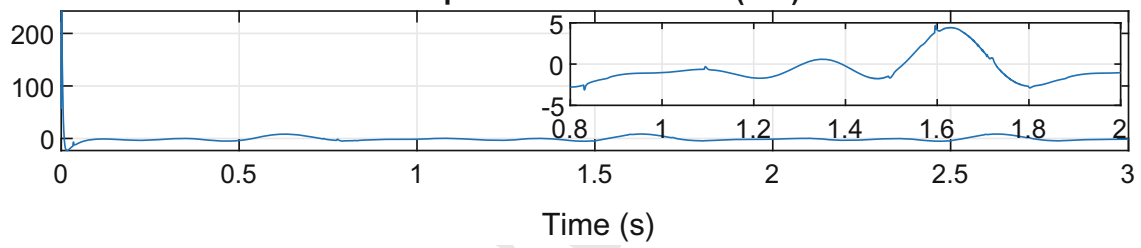

Fig. 7 Adaptive control with integral action of the hip joint. For the position and the speed, dashed line: desired trajectory, solid line: actual trajectory

$$
\begin{gathered}
\tilde{M}(q)=\widehat{M}(q)-M(q)=\sum_{i} M_{i} \widetilde{a}_{i} \\
\widetilde{C}(q, \dot{q})=\widehat{C}(q, \dot{q})-C(q, \dot{q})=\sum_{i} C_{i} \widetilde{a}_{i} \\
\widetilde{G}(q)=\widehat{G}(q)-G(q)=\sum_{i} G_{i} \widetilde{a}_{i}
\end{gathered}
$$

Then, let's write:

$$
\widetilde{M}(q) \ddot{q_{d}}+\widetilde{C}(q, \dot{q}) \dot{q}_{d}+\widetilde{G}(q)=Y \widetilde{a}
$$

where $Y=Y\left(q, \dot{q}, \dot{q}_{d}, \ddot{q}_{d}\right)$ is an $n \times m$ matrix. Therefore:

$$
\dot{V}=-\dot{\tilde{q}}^{T} K_{D} \dot{\tilde{q}}+\widetilde{a}^{T}\left[\Gamma \dot{\tilde{a}}+Y^{T} \dot{\tilde{q}}\right]
$$

Assuming that variations of the unknown vector $a$ can be neglected, we obtain: 

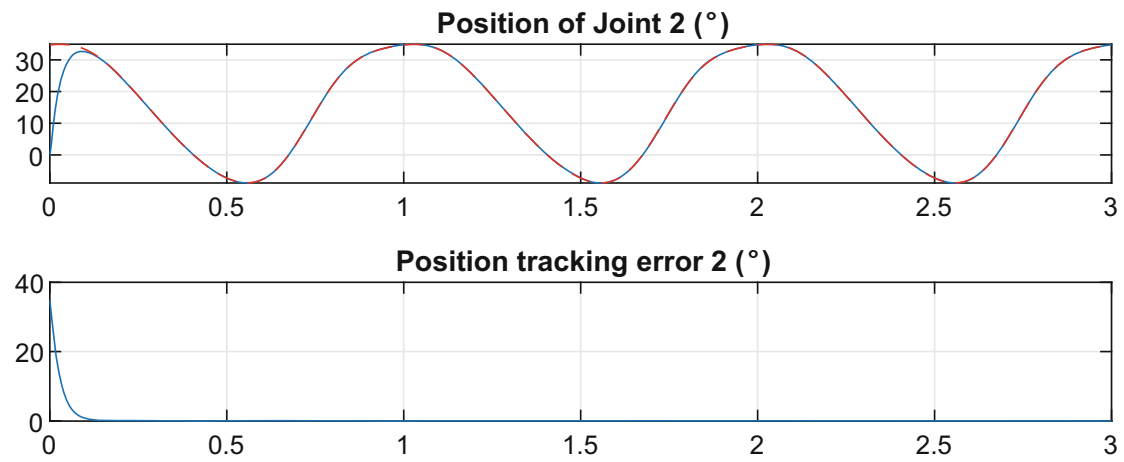

Speed of Joint $2\left({ }^{\circ} / \mathrm{s}\right)$

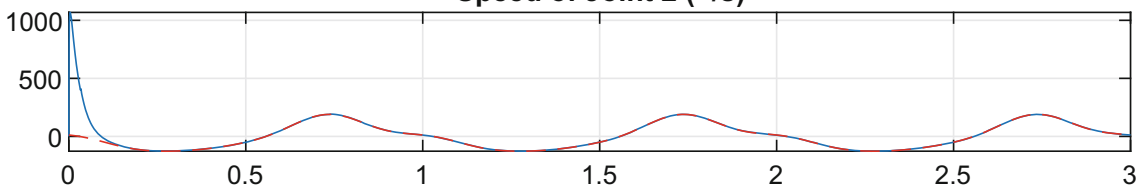

Torque control of Joint 2 (Nm)

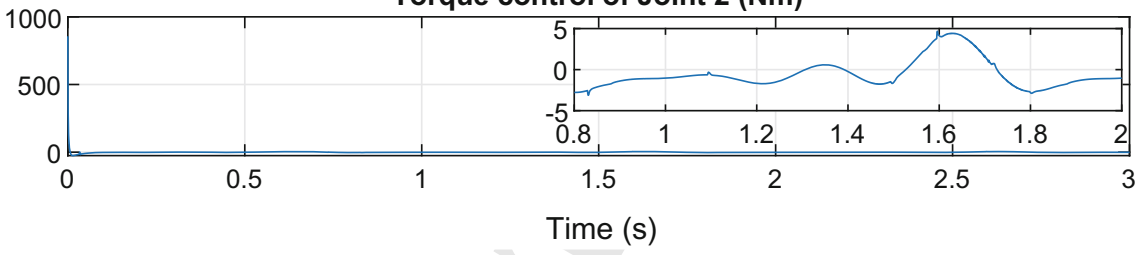

Fig. 8 Adaptive control with integral action of the knee joint. For the position and the speed, dashed line: desired trajectory, solid line: actual trajectory

Table 1 Tracking performance comparison

\begin{tabular}{l|l|l|l|l|l|l}
\hline & \multicolumn{2}{|l|}{ Classical adaptive controller } & \multicolumn{2}{l|}{$L_{1}$ adaptive controller } & \multicolumn{2}{l}{ Augmented $L_{1}$ adaptive controller } \\
\cline { 2 - 7 } & Joint 1 & Joint 2 & Joint 1 & Joint 2 & Joint 1 & Joint 2 \\
\hline$I A E$ & 0.0037 & 0.0169 & 0.0972 & 0.1578 & 0.0054 & 0.0609 \\
\hline$I S E$ & 0.0062 & 0.0181 & 0.0057 & 0.0279 & $1.2702 \times 10^{-4}$ & 0.0183 \\
\hline$I A E R$ & 28.2872 & 3.1664 & 0.4075 & 0.2513 & 0.0228 & 0.0970 \\
\hline
\end{tabular}

$$
\dot{V}=-\dot{\tilde{q}}^{T} K_{D} \dot{\widetilde{q}} \leq 0
$$

using the adaptive law of the parameter vector $a$ :

$$
\dot{\widehat{a}}=-\Gamma^{-1} Y^{T} \dot{\widetilde{q}}
$$



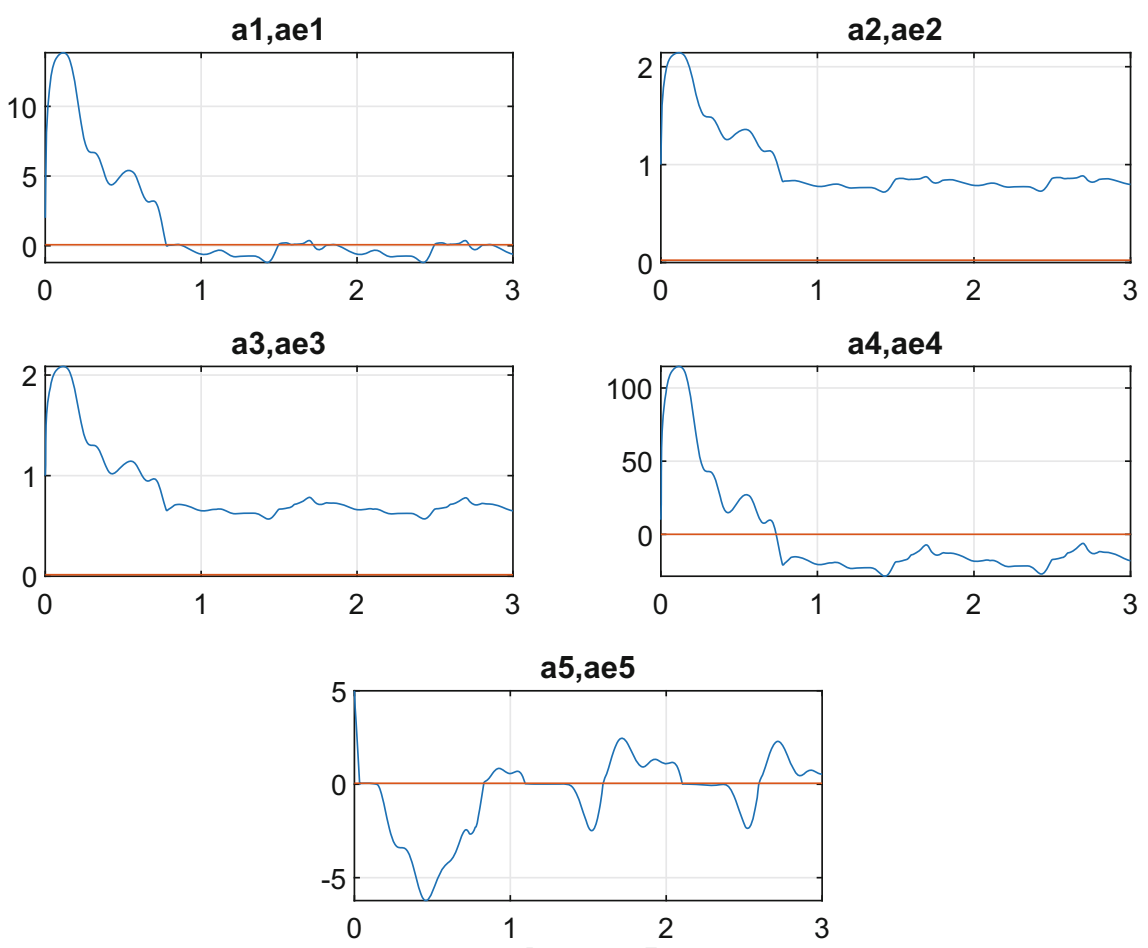

Fig. 9 Evolution of the estimated Parameters for the second adaptive approach of Slotine

\subsection{Adaptive Control with an Integral Action [12]}

The idea is to eliminate the steady-state position errors by restrict them to lie on a sliding surface.

$$
\dot{\widetilde{q}}+\Lambda \widetilde{q}=0
$$

where $\Lambda$ is a positive definite diagonal matrix.

The virtual reference trajectory is expressed by

$$
q_{r}=q_{d}+\Lambda \int \widetilde{q} d t
$$

As a consequence, $\dot{q}_{d}$ and $\ddot{q}_{d}$ are replaced by

$$
\begin{aligned}
& \dot{q}_{r}=\dot{q}_{d}-\Lambda \widetilde{q} \\
& \ddot{q}_{r}=\ddot{q}_{d}-\Lambda \dot{\tilde{q}}
\end{aligned}
$$

If we define 
Position of Joint $1\left(^{\circ}\right)$

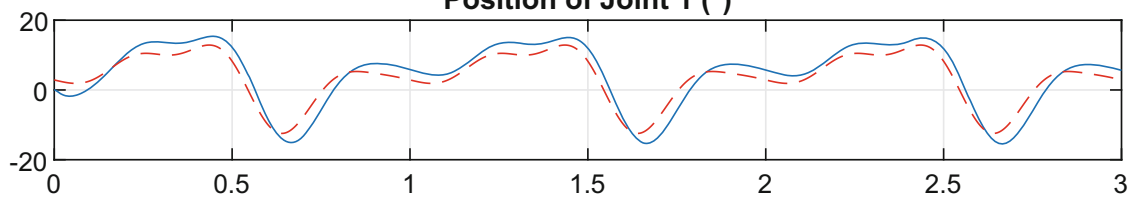

Position Tracking error $1\left(^{\circ}\right)$

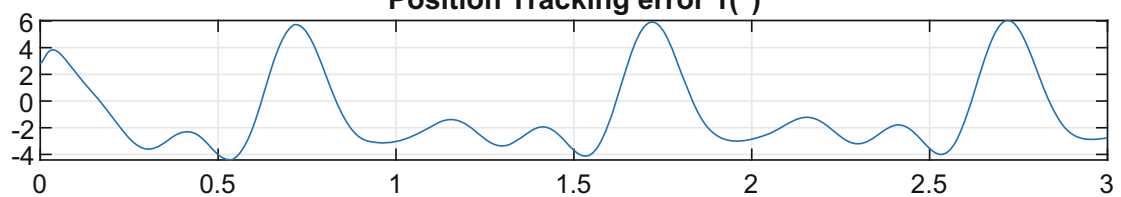

Speed of Joint $1\left({ }^{\circ} / \mathrm{s}\right)$

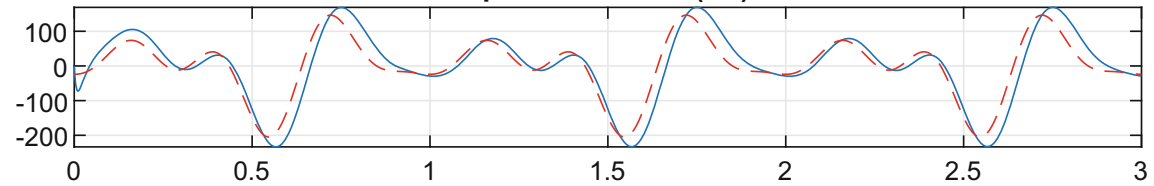

Torque control of Joint $1(\mathrm{Nm})$

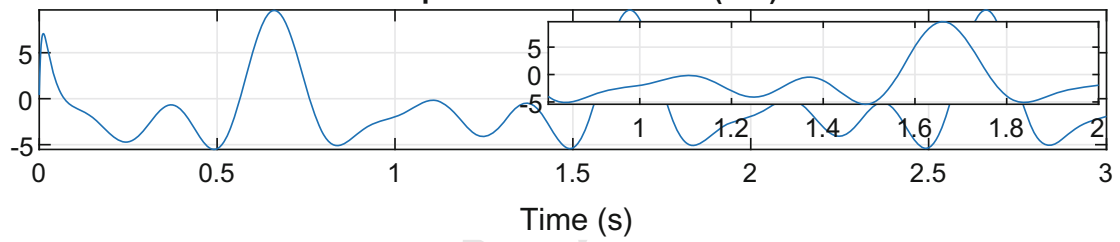

Fig. 10 Classical $L_{1}$ adaptive control of the knee joint. For the position and the speed, dashed line: desired trajectory, solid line: actual trajectory

$$
s=\dot{\widetilde{q}}_{r}=\dot{q}-\dot{q}_{r}=\dot{\widetilde{q}}+\Lambda \widetilde{q}
$$

The control and the adaptation laws become:

We use a Lyapunov function to demonstrate the global convergence of the tracking:

$$
V=\frac{1}{2} s^{T} M s+\frac{1}{2} \widetilde{a}^{T} \Gamma \widetilde{a}
$$

Its first time derivative leads to:

$$
\dot{V}=-s^{T} K_{D} s \leq 0
$$



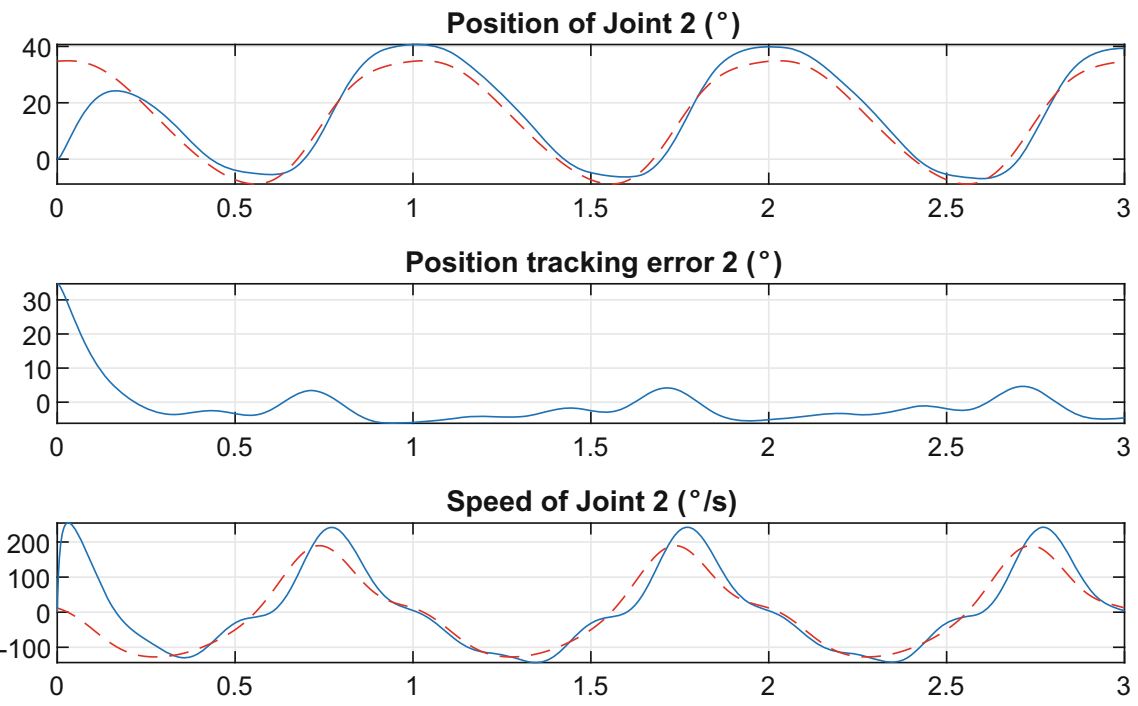

Torque control of Joint $2(\mathrm{Nm})$

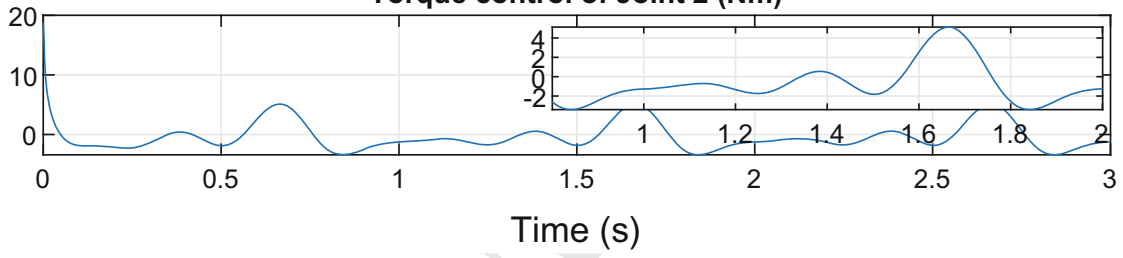

Fig. 11 Classical $L_{1}$ adaptive control of the hip joint. For the position and the speed, dashed line: desired trajectory, solid line: actual trajectory

The control law does not contain $K_{p}$, since the position error $\widetilde{q}$ is already included in $\dot{\widetilde{q}}_{r}$. Moreover where $s$ becomes equal to $0, \widetilde{q}$ converges to 0 .

It is well known that the adaptive controller has several limitations such as (i) the initial value of the parameters, (ii) the persistent excitation of the estimated parameters, and (iii) the stability. Hence, $L_{1}$ Adaptive controller is presented in the next subsection which overcome these limitations.

\subsection{L $L_{1}$ Adaptive Control [2]}

$L_{1}$ adaptive control is inspired from the Model Reference Adaptive Control (MRAC), it is structured into four principal parts as illustrated in Fig. 2 namely the controlled system, the state predictor, the adaptation mechanism and the control law including a low pass filter. Considering that the control input vector $\tau(t)$ is a compound of two 

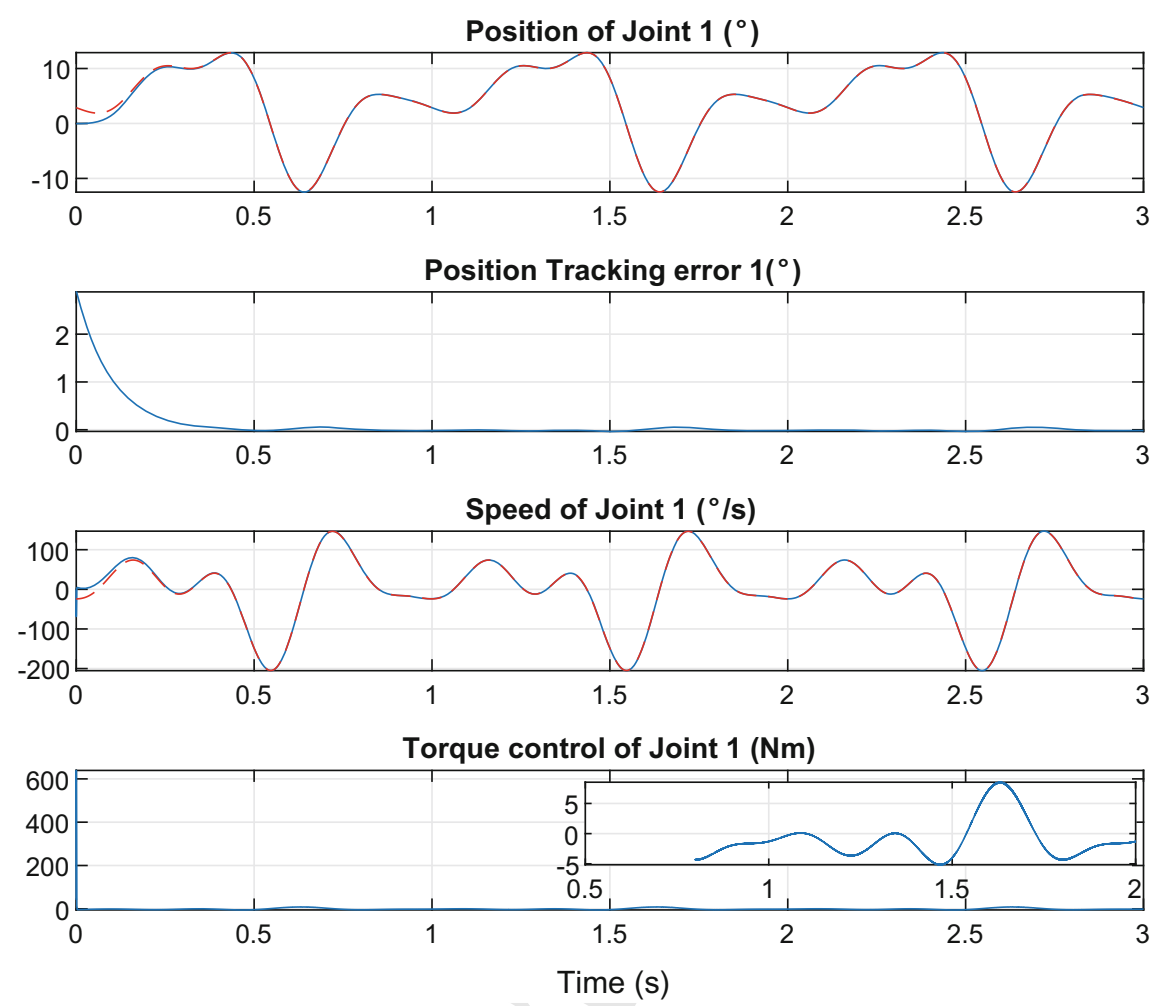

Fig. 12 Position, speed and torque control of the hip joint, obtained with a Augmented $L_{1}$ adaptive controller in the nominal case. Solid line: actual trajectory, dashed line: desired trajectory

parts, a fixed state-feedback term that defines the evolution of the transient response and an adaptive term $\tau_{a d}$ that compensates the nonlinearities of the system.

The expression of the torque is:

$$
\tau(t)=A_{m} r(t)+\tau_{a d}(t)
$$

where:

$A_{m} \in \mathbb{R}^{2 \times 2}$ is a Hurwitz matrix

$\tau_{a d} \in \mathbb{R}^{2 \times 2}$ is the adaptive component

The tracking error is expressed as:

$$
r=\left(\dot{q}-\dot{q}_{d}\right)+\Lambda\left(q-q_{d}\right)
$$



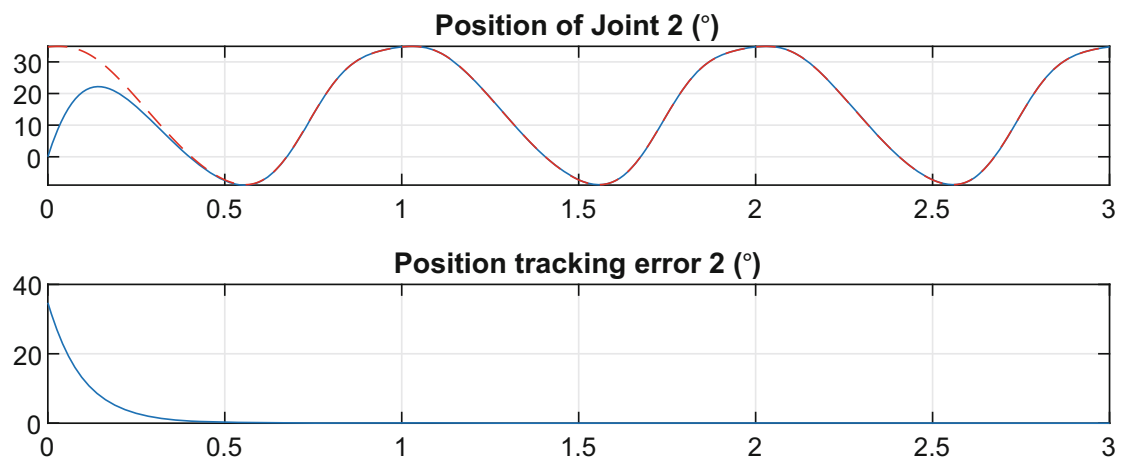

Speed of Joint $2(\%)$

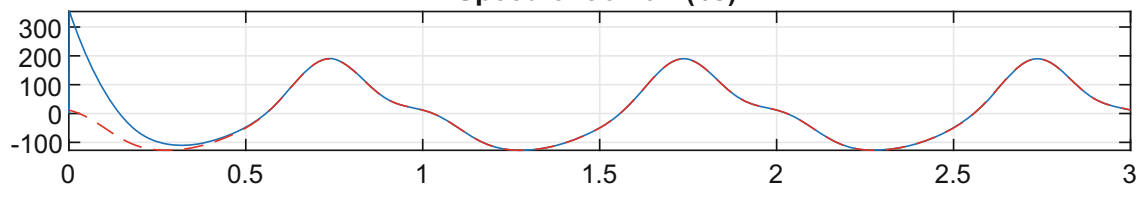

Torque control of Joint 2 (Nm)

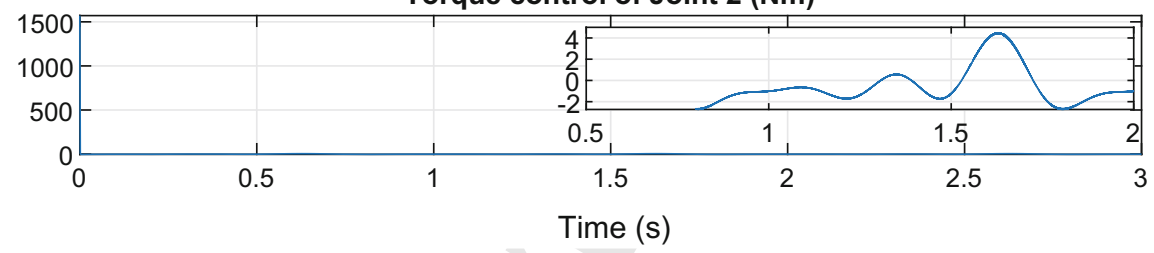

Fig. 13 Position, speed and torque control of the knee joint, obtained with a Augmented $L_{1}$ adaptive controller in the nominal case. Solid line: actual trajectory, dashed line: desired trajectory

with $\Lambda \in \mathbb{R}^{2 \times 2}$ is a symetric positive definite matrix. It is difficult to know exactly all nonlinearities of the system, hence the adaptive control can be defined in such a way to cancel the effect of these nonlinearities. For that, we consider the state predictor which is based on estimated parameters obtained from the adaptation mechanism:

$$
\dot{\hat{r}}=A_{m} \hat{r}(t)+\tau_{a d}(t)-\left[\hat{\theta}(t)\left\|r_{t}\right\|_{\infty}+\hat{\sigma}(t)\right]-K \widetilde{r}(t)
$$

where:

$\widetilde{r}(t)=\hat{r}(t)-r(t)$ is the prediction error

$K \in \mathbb{R}^{2 \times 2}$ used to reject high frequency noises.

Using the projection method, we obtain the estimate of $\theta(t)$ and $\sigma(t)$ :

$$
\begin{aligned}
& \dot{\hat{\theta}}(t)=\Gamma \operatorname{Proj}\left(\hat{\theta}(t), \operatorname{Pr}(t)\left\|r_{t}\right\|_{\infty}\right) \\
& \dot{\hat{\sigma}}(t)=\Gamma \operatorname{Proj}(\hat{\sigma}(t), \operatorname{Pr}(t))
\end{aligned}
$$



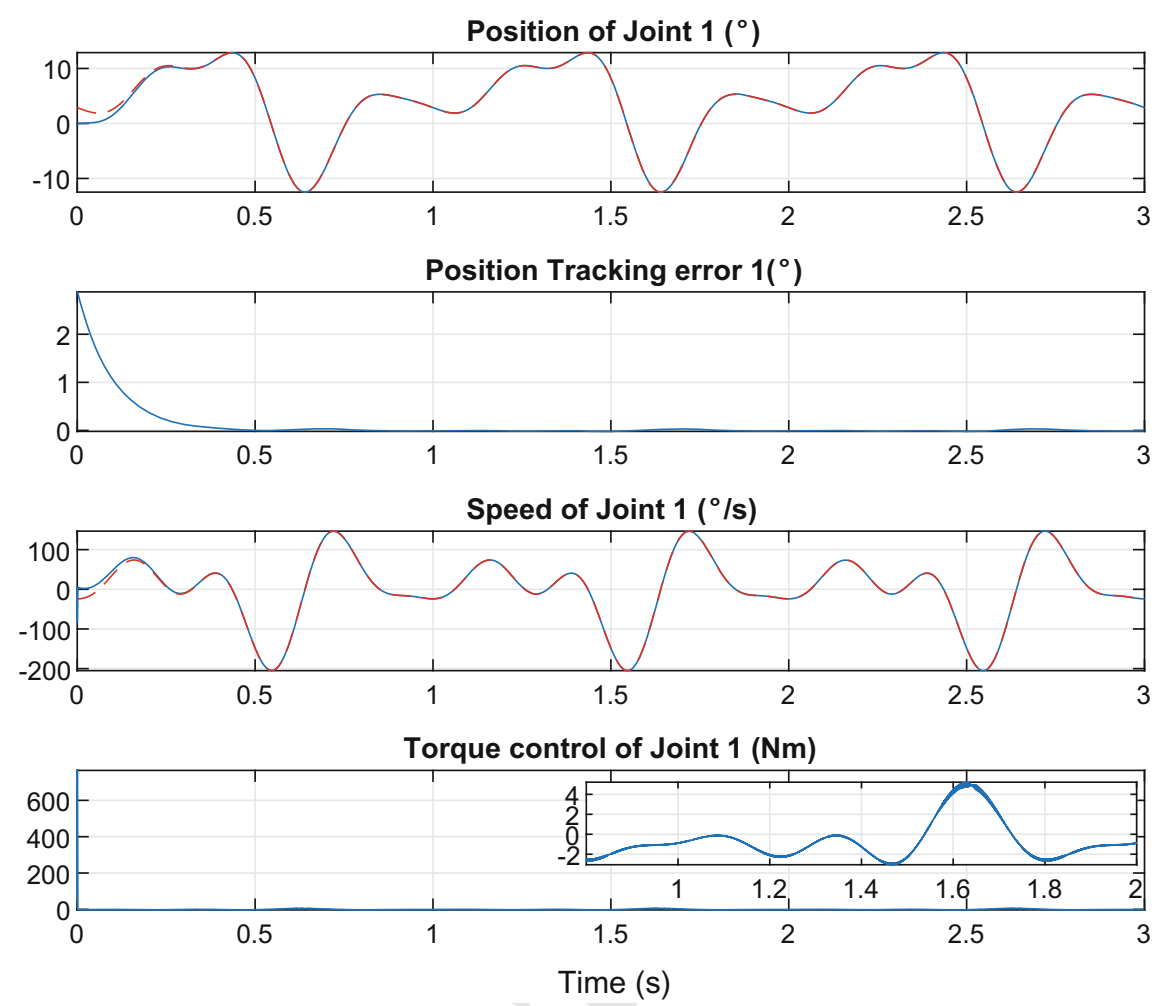

Fig. 14 Influence of $-30 \%$ of masses and $-15 \%$ of length uncertainties on the hip joint tracking with augmented $L_{1}$ adaptive controller

where $\Gamma$ is the adaptive gain.

Let's $P$ the solution of the algebric Lyapunov equation:

$$
A_{m}^{T} P+P A_{m}=-Q
$$

The adaptive control is as follows:

$$
\tau_{a d}(s)=C(s) \hat{\eta}(s)
$$

where $\hat{\eta}(s)$ is the Laplace transform of $\hat{\eta}(t)=\hat{\theta}(t)\left\|r_{t}\right\|_{\infty}+\hat{\sigma}(t)$, and $C(s)$ is a bounded-input bounded-output (BIBO) stable strictly proper transfer function. 

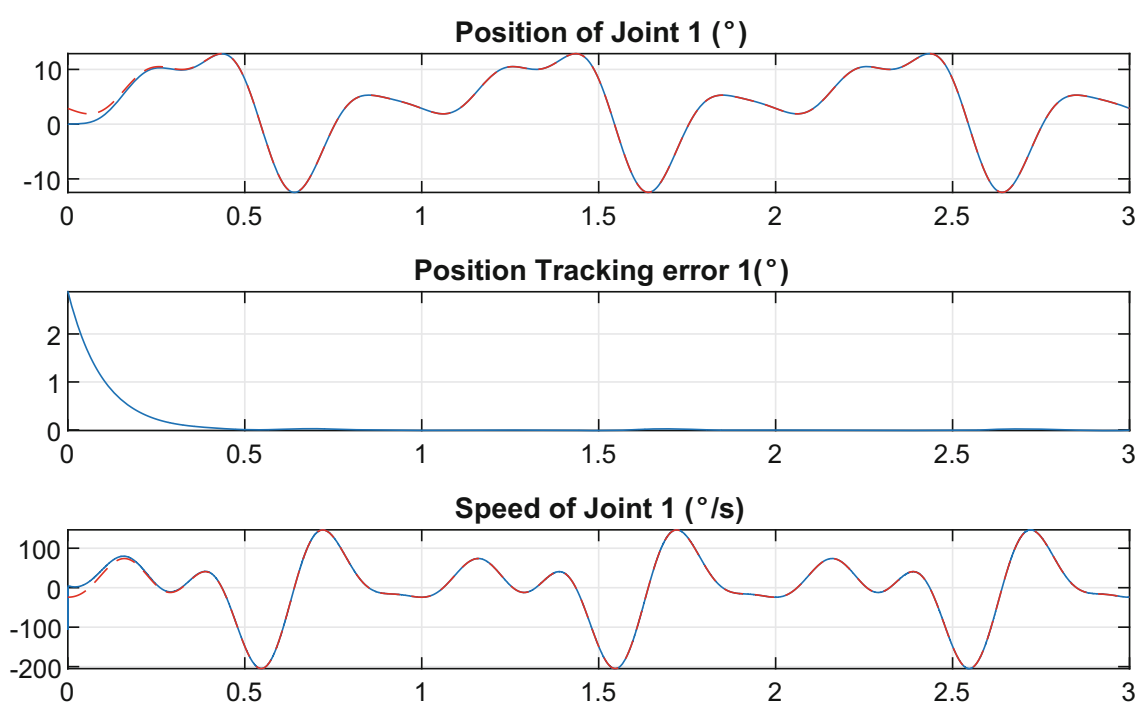

Torque control of Joint 1 (Nm)

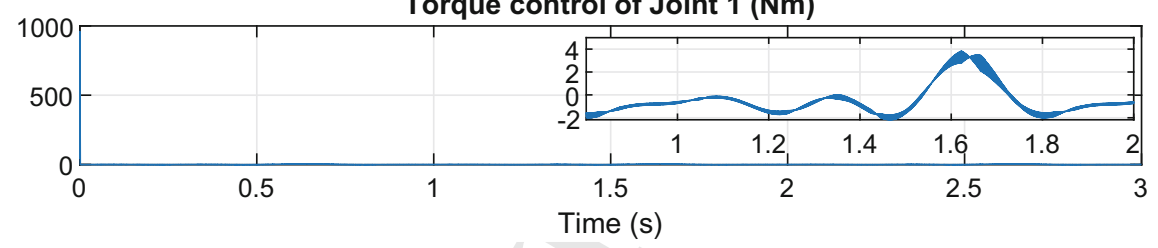

Fig. 15 Influence of $-50 \%$ of masses and $-25 \%$ of length uncertainties on the hip joint tracking with augmented $L_{1}$ adaptive controller

\subsection{Augmented $L_{1}$ Adaptive Control [2]}

The implementation of the classical $L_{1}$ adaptive control indicates the presence of a time lag. Hence, the idea is to develop an augmented version of the $L_{1}$ adaptive control. Figure 3 shows the block diagram of the augmented $L_{1}$ adaptive control. In fact, a linear PI controller is used as an additional part to the filtered control input.

The expression of the torque becomes:

$$
\tau(t)=A_{m} r(t)+\tau_{a d}(t)+K_{p}\left(q-q_{d}\right)+K_{i} \int\left(q-q_{d}\right) d t
$$

where $K_{p}$ and $K_{i} \in \mathbb{R}^{2 \times 2}$ are diagonal positive definite matrices. 

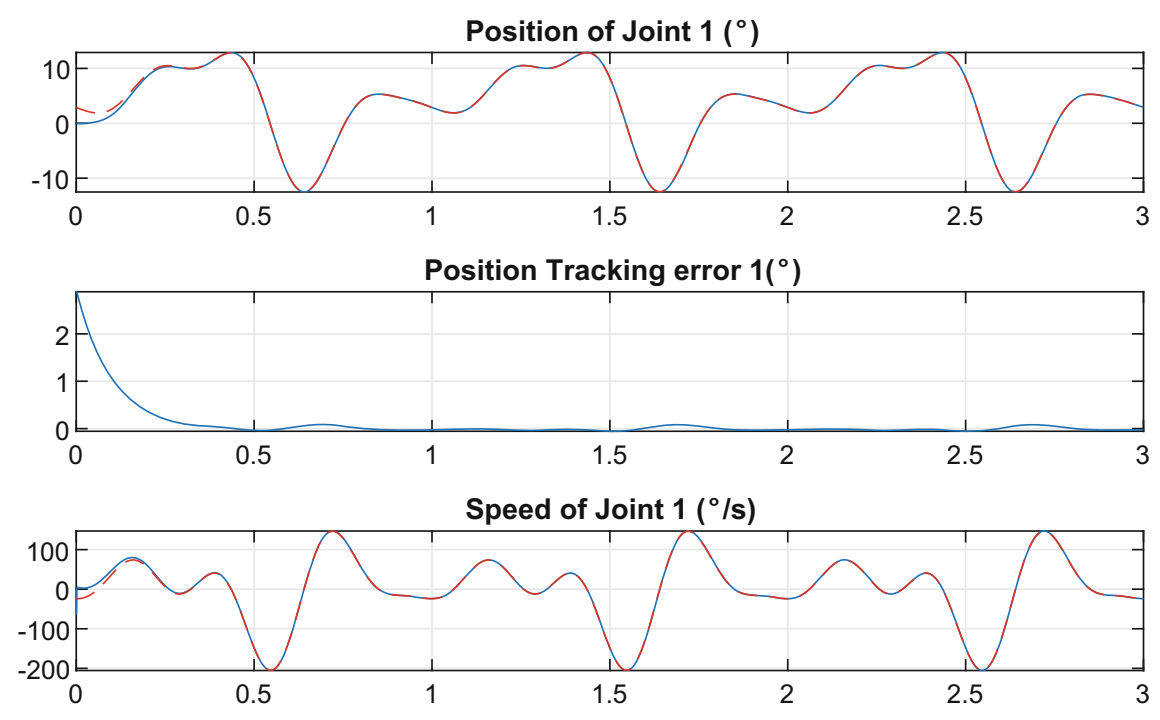

Torque control of Joint 1 (Nm)

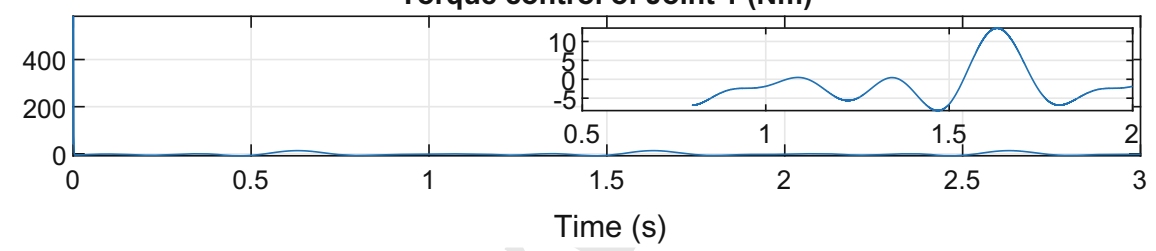

Fig. 16 Influence of $30 \%$ of masses and $15 \%$ of length uncertainties on the hip joint tracking with augmented $L_{1}$ adaptive controller

\section{Simulation Results}

Lower limb exoskeletons are actuated at the knee and hip joints. To validate the different controllers proposed in the previous section, some simulations are presented. First, Figs. 4 and 5 show respectively the position evolution of the hip and the knee joints, the tracking error, their speed and their applied torques using the first approach of Slotine in the nominal case. Besides, Fig. 6 show the convergence of the estimated unknown parameter to the system parameters.

The second part consists in the adaptive control using an integral action. Results are presented in Figs. 7, 8 and 9. 

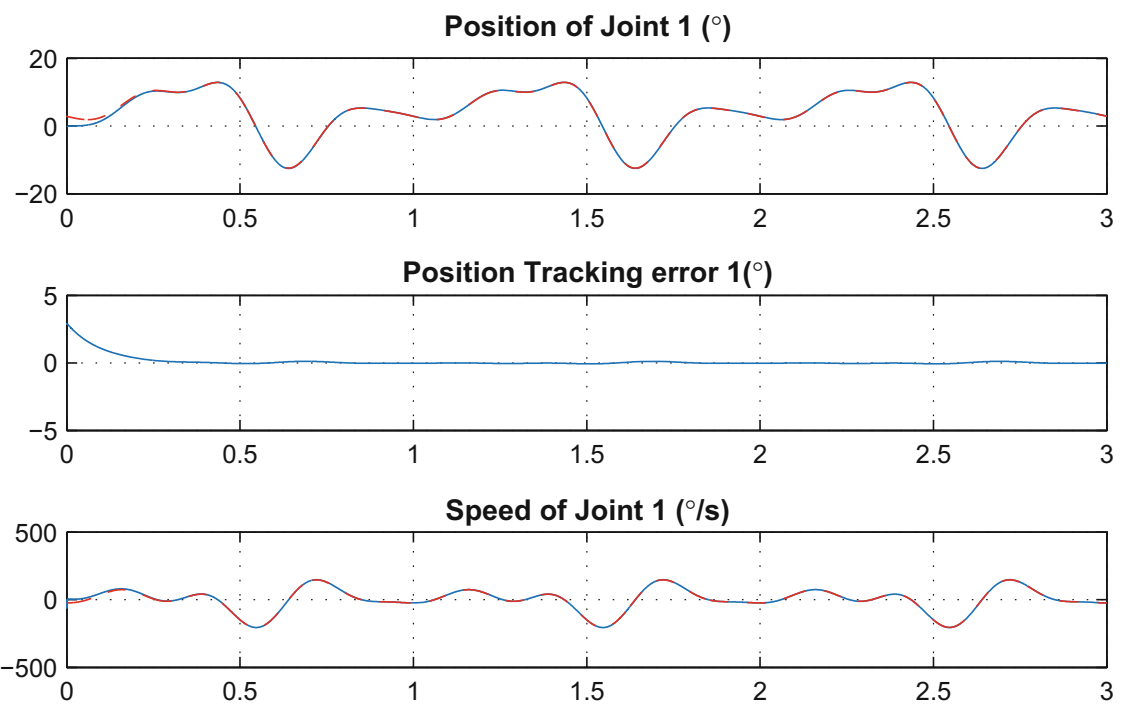

Torque control of Joint $1(\mathrm{Nm})$

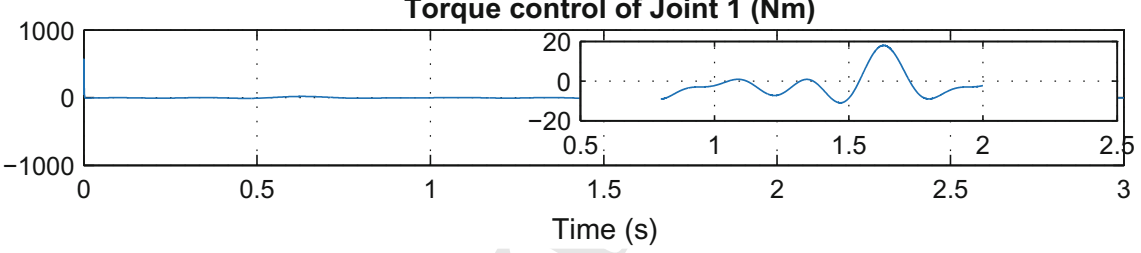

Fig. 17 Influence of 50\% of masses and 25\% of length uncertainties on the hip joint tracking with augmented $L_{1}$ adaptive controller

These figures show a good tracking of the desired trajectories using the second approach of Slotine.

Then, a classical $L_{1}$ adaptive control is implemented. Figures 10 and 11 show a time lag between the actual and the desired trajectory. Hence, the idea of implementing an augmented $L_{1}$ adaptive control. The obtained results are illustrated in Figs. 12 and 13, and show a good tracking of the desired reference trajectories.

In order to prove the robustness of the proposed extended $L_{1}$ adaptive control. First, we demonstrate the performance of the proposed controllers using three criteria named as (i) the Integral of the Absolute Error (IAE), (ii) the Integral of the Squared Error (ISE) and (iii) the relative integral of absolute error (IAER): 

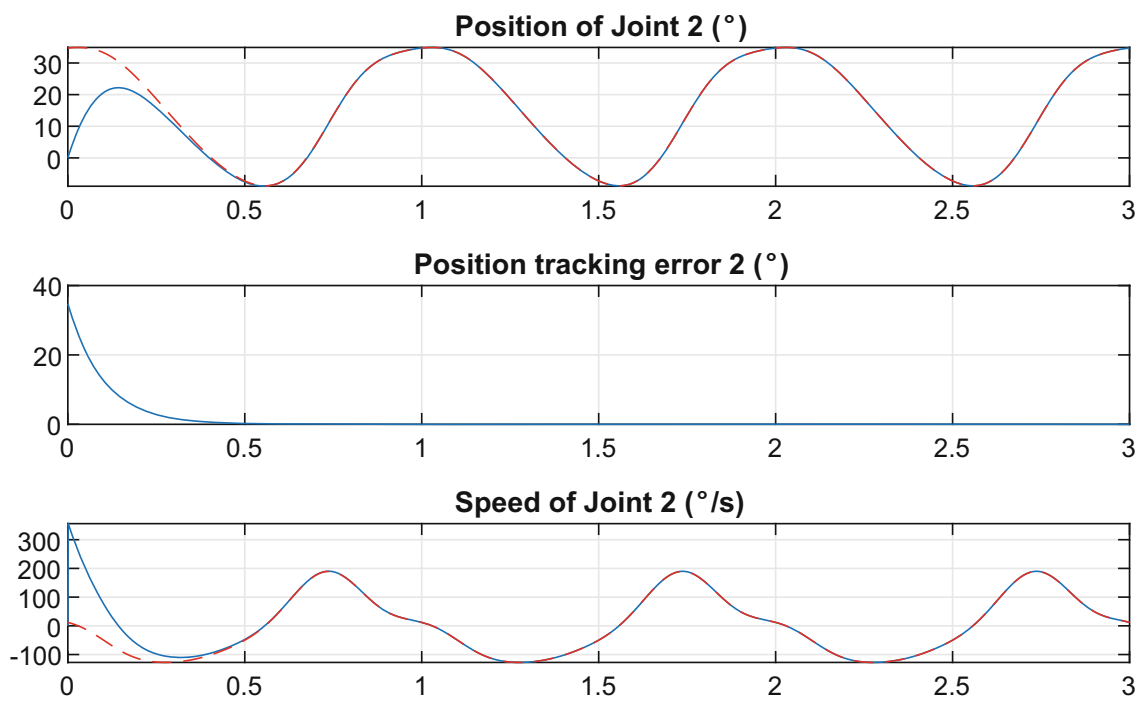

Torque control of Joint $2(\mathrm{Nm})$

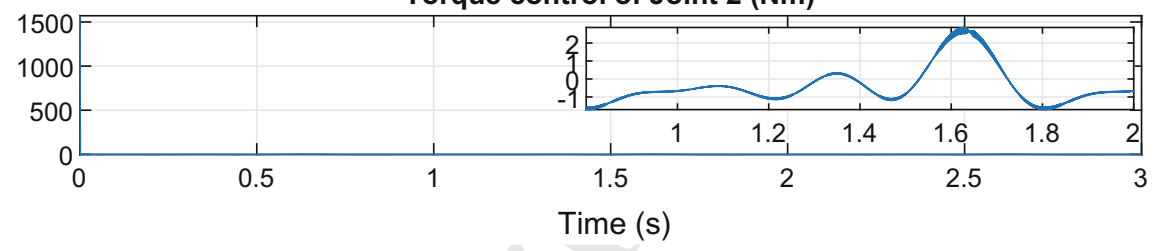

Fig. 18 Influence of $-30 \%$ of masses and $-15 \%$ of length uncertainties on the knee joint tracking with augmented $L_{1}$ adaptive controller

$$
\begin{aligned}
I A E & =\int|e| d t \\
I S E & =\int e^{2} d t \\
I A E R & =\frac{\int|e| d t}{\int\left|q_{d}\right| d t}
\end{aligned}
$$

$e$ denotes the tracking error.

The obtained results are summarized in Table 1. 

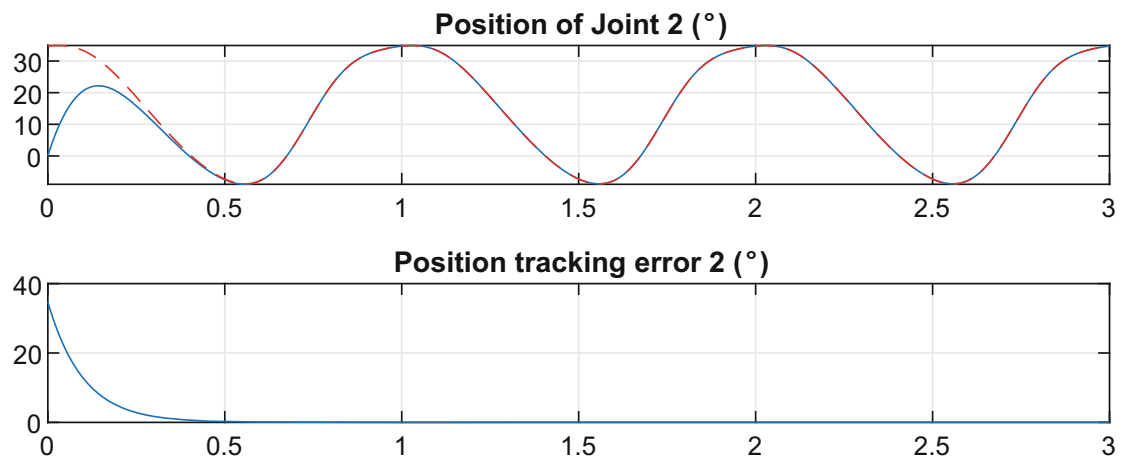

Speed of Joint $2(\% / s)$

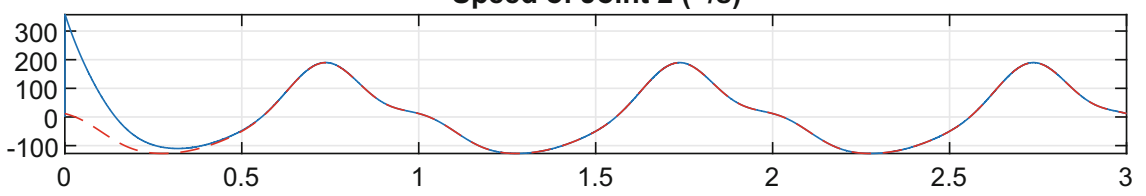

Torque control of Joint 2 ( $\mathrm{Nm})$

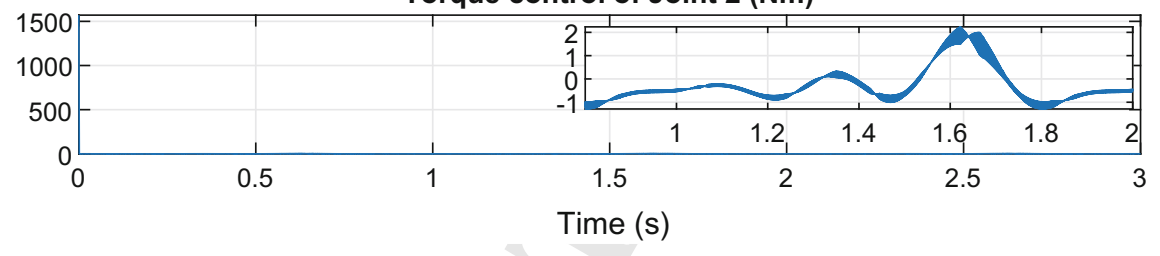

Fig. 19 Influence of $-50 \%$ of masses and $-25 \%$ of length uncertainties on the knee joint tracking with augmented $L_{1}$ adaptive controller

Figures 14, 15, 16 and 17 present the evolution of positions, velocities, applied torques and position errors of the hip joint in the presence of mass variations of \pm 30 and $\pm 50 \%$ and leg length variations of \pm 15 and $\pm 25 \%$.

Figures 18, 19, 20 and 21 present the evolution of positions, velocities, applied torques and position errors of the knee joint in the presence of mass variations of \pm 30 and $\pm 50 \%$ and leg length variations of \pm 15 and $\pm 25 \%$.

In both cases, results show a good tracking of the desired trajectories in the presence of parametric variations with performant torques values. Thus, it is well obvious the good performances observed by the augmented $L_{1}$ adaptive control. 

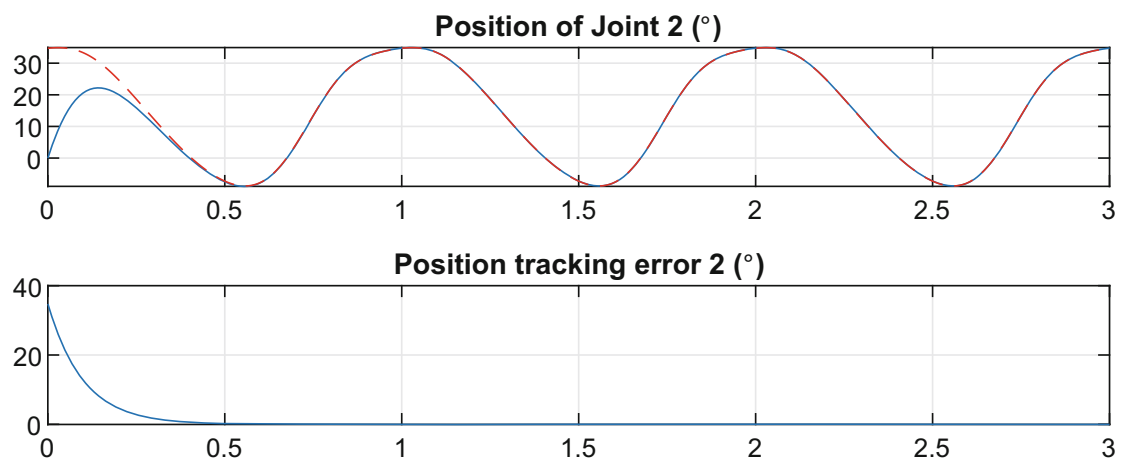

Speed of Joint $2(\% / s)$

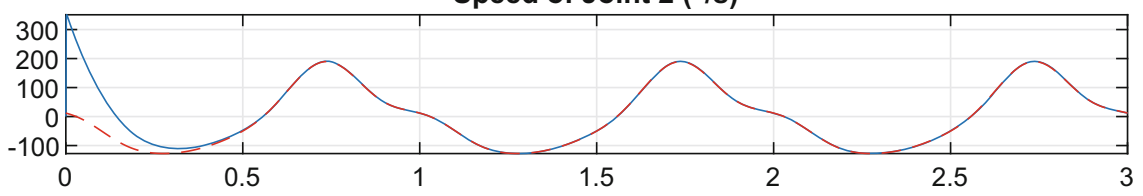

Torque control of Joint 2 ( $\mathrm{Nm})$

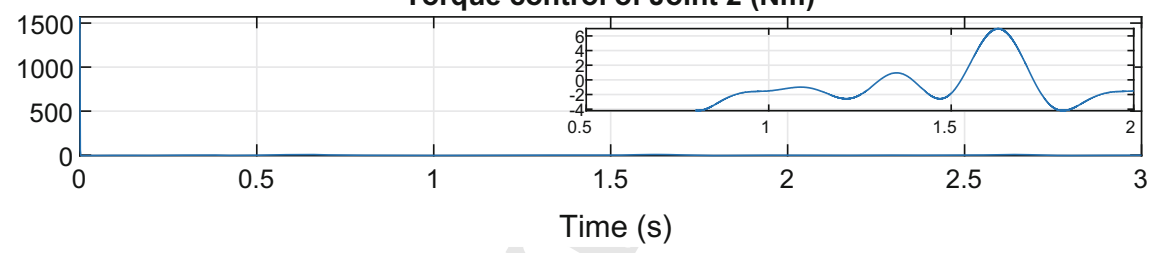

Fig. 20 Influence of $30 \%$ of masses and $15 \%$ of length uncertainties on the knee joint tracking with augmented $L_{1}$ adaptive controller

\section{Conclusion and Future Work}

In this work, four adaptive controllers have been proposed and implemented to control an exoskeleton for kids rehabilitation. These control laws have been tested for the tracking of walking cycle desired trajectory. This study concerns kids who have between 2 and 13 years old (i.e. with different morphologies). Through numerical simulations, it has been shown that the augmented $L_{1}$ adaptive controller is the best one in terms of robustness against these parametric variations. Future works aim to validate the proposed approaches on a real exoskeleton, as well as the application to the targeted kids therapy. 
Position of Joint $2\left(^{\circ}\right)$
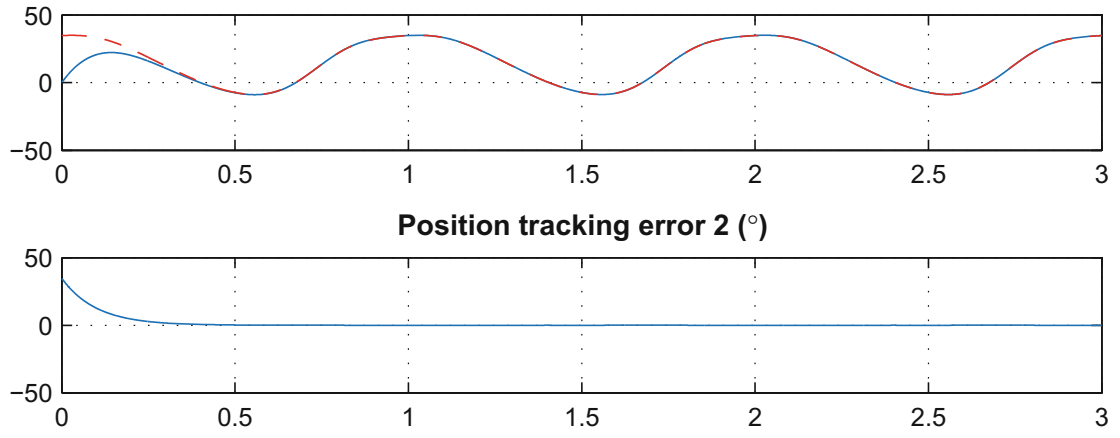

Speed of Joint $2(\%)$

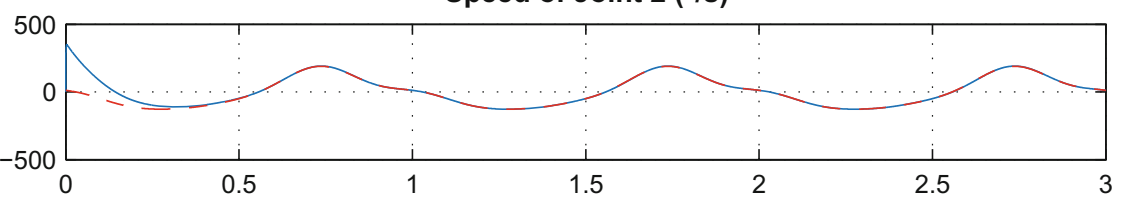

Torque control of Joint 2 (Nm)

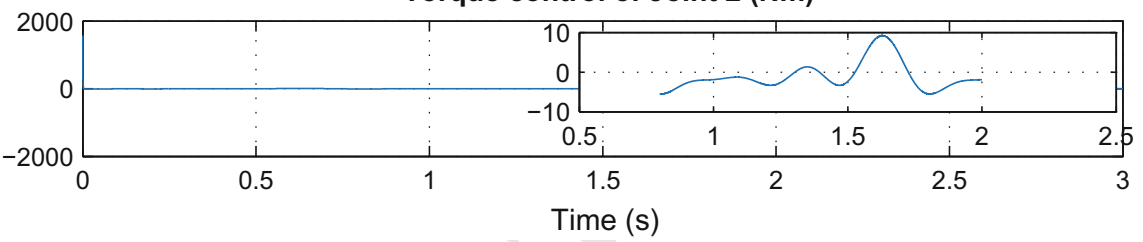

Fig. 21 Influence of 50\% of masses and $25 \%$ of length uncertainties on the knee joint tracking with augmented $L_{1}$ adaptive controller

Acknowledgements The present work is supported by (i) the "Association de Sauvegarde des Handicapés Moteurs - Sfax" (ASHMS), the (ii) Clinical Inverstigation Center (CIC) of the Hospitalo-University Center of Sfax (CHU) Tunisia, (iii) the Laboratory "Control \& Energy Managements" (CEMLab) of the "National School of Engineering of Sfax", University of Sfax, Tunisia, and (iv) the Digital Research Center of Sfax, Tunisia (CRNS).

\section{References}

1. Adams, E.: Power-multiplying exoskeletons are slimming down for use on the battlefield (2017). https://www.popsci.com/army-exoskeletons-lockheed-martin [online]

2. Bennehar, M., Chemori, A., Pierrot, F.: L1 adaptive control of parallel kinematic manipulators: design and real-time experiments. In: IEEE International Conference on Robotics and Automation, pp. 157.87-1592 (2015)

3. Deep, A., Jaswal, R.:Role of management and virtual space for the rehabilitation of children affected with cerebral palsy: a review. In: IEEE International Conference on Signal Processing, Computing and Control, pp. 293-299 (2017) 
4. Duschau-Wicke, A., Brunsch, T., Lünenburger, L., Riener, R.: Adaptive support for patientcooperative gait rehabilitation with the lokomat. In: IEEE International Conference on Intelligent Robots and Systems, pp. 2357-2361 (2007)

5. Ghezal, M., Guiatni, M., Boussioud, I., Renane, C.S.: Design and robust control of a 2 DOFs lower limb exoskeleton. In: International Conference on Communications and Electrical Engineering (2018)

6. Hesse, S., Schmidt, H., Werner, C., Bardeleben, A.: Upper and lower extremity robotic devices for rehabilitation and for studying motor control. Curr. Opin. Neurol., 705-710 (2003)

7. Hovakimyan, N., Cao, C.: L1 adaptive control theory guaranted robustness with fast adaptation. Adv. Des. Control (2010)

8. Jamshidi, N., Rostami, M., Najarian, S., Menhaj, M.B., Saadatnia, M., Firooz, S.: Modelling of human walking to optimise the function of ankle-foot orthosis in Guillan-Barre patients with drop foot. Singap. Med. J. 50(4), 412-737 (2009)

9. Refai, H., Ben Abdessalem, M.S., Chemori, A., Mohammed, S., Amirat, Y.: Augmented L1 adaptive control of an actuated knee joint exoskeleton: from design to real-time experiments. In: IEEE International Conference on Robotics and Automation, ICRA, pp. 5707.8-5714 (2016)

10. Refai, H., Mohammed, S., Daachi, B., Amirat, Y.: Adaptive control of a human-driven knee joint orthosis. In: IEEE International Conference on Robotics and Automation, pp. 247.862491 (2012)

11. Rupal, B., Rafique, S., Singla, A., Singla, E., Isaksson, M., Virk, G.: Lower-limb exoskeletons: research trends and regulatory guidelines in medical and non-medical applications. Int. J. Adv. Robot. Syst., 1-27 (2017)

12. Slotine, J.-J.E., Li, W.: On the adaptive control of robot manipulators. Int. J. Robot. Res., 49-59 (1987)

13. Tucker, M., Olivier, J., Pagel, A., Bleuler, H., Bouri, M., Lambercy, O., Millán, J., Riener, R., Vallery, H., Gassert, R.: Control strategies for active lower extremity prosthetics and orthotics: a review. J. Neuroeng. Rehabil., 1-12 (2015)

14. Zeilig, G., Weingarden, H., Obuchov, A., Bloch, A., Gaides, M., Reuveny, R., Ben-Dov, I.: Lokomat walking results in increased metabolic markers in individuals with high spinal cord injury. In: International Conference on Virtual Rehabilitation, ICVR, pp. 119-120 (2015) 


\section{Author Queries}

Chapter 6

\begin{tabular}{|c|l|c|}
\hline Query Refs. & Details Required & Author's response \\
\hline AQ1 & $\begin{array}{l}\text { References }[1-4,7,12-14] \text { are given in the list but not cited in the } \\
\text { text. Please cite them in text or delete them from the list. }\end{array}$ & \\
\hline
\end{tabular}




\section{Please correct and return this set}

Please use the proof correction marks shown below for all alterations and corrections. If you wish to return your proof by fax you should ensure that all amendments are written clearly in dark ink and are made well within the page margins.

\begin{tabular}{|c|c|c|}
\hline Instruction to printer & Textual mark & Marginal mark \\
\hline Leave unchanged & ... under matter to remain & ( $)$ \\
\hline $\begin{array}{l}\text { Insert in text the matter } \\
\text { indicated in the margin }\end{array}$ & $\Lambda$ & $\begin{array}{l}\text { New matter followed by } \\
h \text { or } h \otimes\end{array}$ \\
\hline Delete & $\begin{array}{l}\text { I through single character, rule or underline } \\
\text { or }\end{array}$ & $\sigma$ or $\sigma / 2$ \\
\hline $\begin{array}{l}\text { Substitute character or } \\
\text { substitute part of one or } \\
\text { more word(s) }\end{array}$ & I through letter or & $\begin{array}{l}\text { new character / or } \\
\text { new characters / }\end{array}$ \\
\hline Change to italics & — under matter to be changed & $\leftarrow$ \\
\hline Change to capitals & $\equiv$ under matter to be changed & $\equiv$ \\
\hline Change to small capitals & $=$ under matter to be changed & $=$ \\
\hline Change to bold type & $\sim$ under matter to be changed & $\sim$ \\
\hline Change to bold italic & $\bar{\sim}$ under matter to be changed & 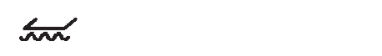 \\
\hline Change to lower case & Encircle matter to be changed & $\Rightarrow$ \\
\hline Change italic to upright type & (As above) & \\
\hline Change bold to non-bold type & (As above) & nor \\
\hline Insert 'superior' character & $\begin{array}{l}/ \text { through character or } \\
\alpha \text { where required }\end{array}$ & $\begin{array}{l}y^{\prime} \text { or } y \\
\text { under character } \\
\text { e.g. } y^{2} \text { or } y^{2}\end{array}$ \\
\hline Insert 'inferior' character & (As above) & $\begin{array}{l}\lambda \\
\text { over character } \\
\text { e.g. } \hat{\Sigma}\end{array}$ \\
\hline Insert full stop & (As above) & $\odot$ \\
\hline Insert comma & (As above) & , \\
\hline Insert single quotation marks & (As above) & $\begin{array}{l}\dot{y} \text { or } \dot{x} \text { and/or } \\
\dot{y} \text { or } \dot{y}\end{array}$ \\
\hline Insert double quotation marks & (As above) & $\begin{array}{l}\ddot{y} \text { or } \ddot{x} \text { and/or } \\
\ddot{y} \text { or } \ddot{x}\end{array}$ \\
\hline Insert hyphen & (As above) & 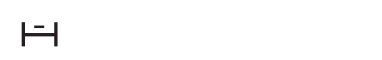 \\
\hline Start new paragraph & 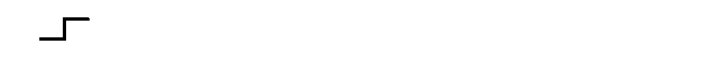 & 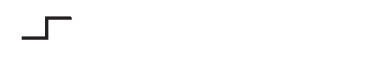 \\
\hline No new paragraph & 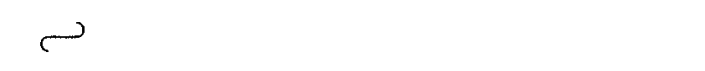 & 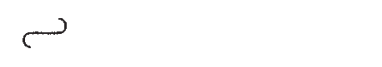 \\
\hline Transpose & $\sqcup$ & $\sqcup$ \\
\hline Close up & linking $\bigcirc$ characters & \\
\hline $\begin{array}{l}\text { Insert or substitute space } \\
\text { between characters or words }\end{array}$ & $\begin{array}{l}\text { I through character or } \\
\Lambda \text { where required }\end{array}$ & \\
\hline $\begin{array}{l}\text { Reduce space between } \\
\text { characters or words }\end{array}$ & $\begin{array}{l}\text { between characters or } \\
\text { words affected }\end{array}$ & $\uparrow$ \\
\hline
\end{tabular}

